\title{
Development of work breakdown structure (WBS) dictionary for the construction works of lower structure steel bridge
}

\author{
Yusuf Latief, Dina Nurdiani, and Leni Sagita Riantini Supriadi* \\ Civil Engineering Department, Faculty of Engineering, Universitas Indonesia, Kampus Baru UI, Depok, 16424, Jawa Barat, \\ Indonesia
}

\begin{abstract}
The lower structure of a steel bridge is one of the essential elements of a whole steel bridge structure. The construction works of this structure are complex and extensive. In the process of planning the construction works for this element, thorough and well-designed plan is vital in order to avoid construction failures or defects that could lead to project failure. Therefore, in the construction planning process for the lower structure steel bridge, a detailed construction process and activities, including its resources are needed for guiding the process effectively and comply with the project requirements. The decomposition of the construction works into work packages is important to minimize mistakes, which is by using a definitive work breakdown structure (WBS) and its detailed dictionary for each work packages. The objective of this study is to develop the WBS dictionary based on the defined WBS, for each construction work elements in the lower structure steel bridge. The study used Delphi method and expert validation as its methodology. The result provides the WBS dictionary that specifies the construction works of lower structure steel bridge into four (4) levels of WBS and two (2) supplementary levels of detailed activities and resources.
\end{abstract}

\section{Introduction}

Steel frame bridges with the main principle of triangular configuration elements are widely used in bridge construction. Steel frame bridges are considered more advantageous compared to other bridge construction systems because steel frame rods only accept tensile and compressive forces resulting in a stable shape. The construction work of the bridge is a costly job, therefore it is needed to calculated and planned carefully so that the cost incurred in accordance with the budget cost and does not lead to cost swelling [1].

In the process of achieving the final outcome, project activities are limited by budget, schedule and quality, known as triple constraints. These three constraints are important parameters for project organizers who are often associated with project objectives [2]. Planning a project is quite complicated in breaking down work into smaller work elements. In addition, unclear job descriptions can result in project losses, scalable and uncontrolled project scope, project cost swelling, errors in determining project time targets resulting in delays in the construction process of a project due to the timing of project implementation [3]. Therefore it needs a standard or guideline used in planning to avoid problems that could hamper the project.
The initial phase of project planning in the scope of management, after defining the scope of work and the needs of the project is carried out the development of Work Breakdown Structure (WBS) on the construction project [2]. To define each work packet as specified on the WBS properly requires a WBS dictionary [4]. The WBS dictionary is used during the planning process, especially when planning the resources needed to prepare the project plan [5].

WBS dictionary is also used during project execution, validation of deliverables can be done based on WBS and WBS dictionary. The Work Breakdown Structure and its dictionaries are often used as baselines to measure the 'wants' and 'needs' of projects that have been approved in advance so that the results match the scope of the project [4].

The development of WBS dictionary in this study has the following objectives:

1. Identify and arrange work packages on the lower structure steel bridge construction work.

2. Identify the various methods of implementation carried out on the work package of substructure in steel bridge.

3. Identify the required activities of each implementation method on the substructure work package.

\footnotetext{
* Corresponding author: 1sagita@eng.ui.ac.id
} 
4. Identify the resources of each activity of each implementation method on the packet required in the work of substructure in steel bridge.

5. Identify the form of WBS dictionary on the lower structure of steel bridge.

\section{Literatur Review}

\subsection{Lower Structure of Steel Bridge}

Part of the bridge can be divided into two, the upper and lower structures of the bridge. The lower structure or substructure is the part which bears the beam of the upper structure and other loads caused by soil pressure, water pressure and others which are then channeled into the foundation and received by the soil. According to Chen and Duan [6], the structure under the bridge is divided into several parts as follows:

1. Abutment

This abutment plays a role in connecting bridges with roads and holding back the foundation material with bridge spans. The function of the abutment of the bridge is as follows:

- As beam bridge or beam placement;

- As placement of stamped plate;

- As the successors of forces acting on the upper structure to the foundation;

- As an active pressure retaining of the soil;

- As a supporter of the upper buildings and also as a retaining land.

\section{Pier / Column}

The pier or bridge pillar is a bridge bottom element that provides vertical support for the bridge spans and has two main functions: forwarding the vertical load from the bridge overhead structure to the foundation and holding the horizontal force on the bridge. In addition, the pier/column is designed to withstand high lateral loads caused by earthquakes.

3. Foundation

The foundation is the lowest part of the building that passes the burden of the building to the ground or the rock beneath it [7].

The illustration of a steel structure can be seen in Figure 1 .

\subsection{WBS (Work Breakdown Structure)}

WBS (Work Breakdown Structure) creation is a process for dividing or breaking project deliverables and project work into smaller components for easier arrangement [2]. The main objective of making WBS is to facilitate the planning and controlling costs, schedule and technical content of the project. Therefore WBS manufacture is done during the initial phase of project development.

WBS-oriented deliverables provide the following benefits to the project, ie [8]:

- Better communication between sponsors, stakeholders and team members,

- More accurate estimates for jobs, risks, timelines and costs,

- Increase confidence that the project has been $100 \%$ identified,

- As the foundation for project control.

\subsection{WBS Dictionary}

The WBS dictionary is a document in which the components of the work are descripted [9]. The WBS dictionary provides details on WBS regarding each work packet and summary of the information on the work package [10].

The WBS dictionary is developed after WBS is created, each level of WBS is given detail and code that gives the following functions:

- WBS dictionary gives every element of WBS

- The WBS dictionary describes the resources needed to run a job

- The WBS dictionary describes the process that must be followed to complete the descriptive job

Information in the WBS dictionary includes the following [10]:

- Code of account identifier

- Description of work

- Assumption and constraints

- Responsible organization or person

- List of milestone

- List of schedule activities

- Resources required

- Cost estimates

- Quality requirements

- Acceptance criteria

- Technical information or references

- Agreement (contract) information 


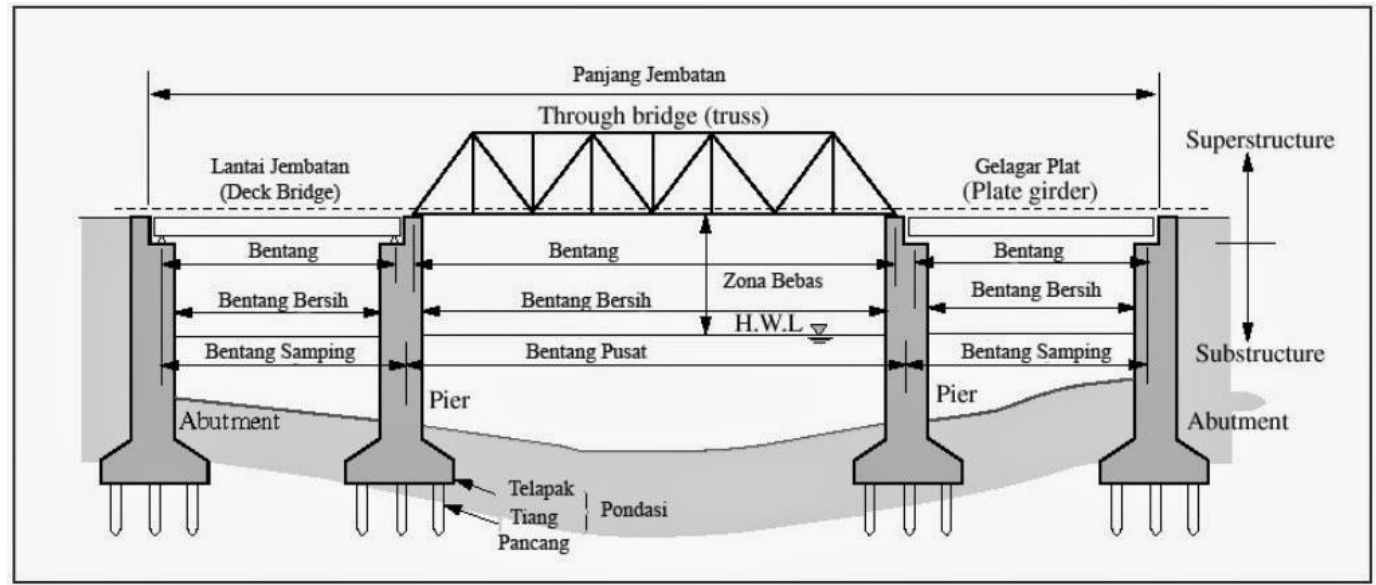

Fig. 1. Steel structure [6]

\section{Methodology}

The research methodology used in this study is as follows:

- Identify the standard WBS for the construction of the lower structure in steel bridge by conducting an archive analysis of the previous research, which is the Development of Standard WBS (Work Breakdown Structure) based Project Planning Risk on Steel Bridge.

- Develop a WBS dictionary by conducting archive analysis, interviews and validation of expert using Delphi Technique in the field of WBS and steel bridge construction.

\section{Result and Discussion}

The Work Breakdown Structure on steel bridge resulting from previous research has 6 levels consisting of 10 divisions. The undefined WBS levels consist of:

WBS Level 1 : Project Name,

WBS Level 2 : Working Group / Division,

WBS Level 3 : Sub of work,

WBS Level 4 : Work Packages,

WBS Level 5 : Activities,

WBS Level 6 : Resources.

While the 10 defined divisions are composed of:

Division 1 : General,

Division 2 : Drainage,

Division 3 : Earth Works,

Division 4 :Pavement Widening and
Division 5 : Concrete Powder and Concrete Cement,

Division 6 : Asphalt Pavement,

Division 7 : Structure,

Division 8 : Restoration Condition,

Division 9 : Daily Work

Division 10 : Daily Maintenance.

The WBS is based on the three archival data, the General Specification of Highways 2010 Revision 3, the Special Specification of Expressway and Toll Road 2017 and the Bridge Project Data Report. For more details can be seen in Figure 2.

After obtaining the WBS level and division, then the development of WBS was done by arranging based on archive data analysis of previous projects. This stage contain of interviews and validation experts who are experienced in the field of WBS-based construction project planning and steel bridge construction.

Validation is performed on five experts with a minimum of 10 years experience and minimum of master degree. The results obtained from this stage are in the form of the entire WBS steel bridge construction project.

However, since the whole steel bridge construction project is a complex job and has a wide scope, this paper will only discuss more about Division 7 which is on the bottom of the bridge (substructure). The following is the detail of WBS structural division for steel bridge, which is as follows in Figure 3. 


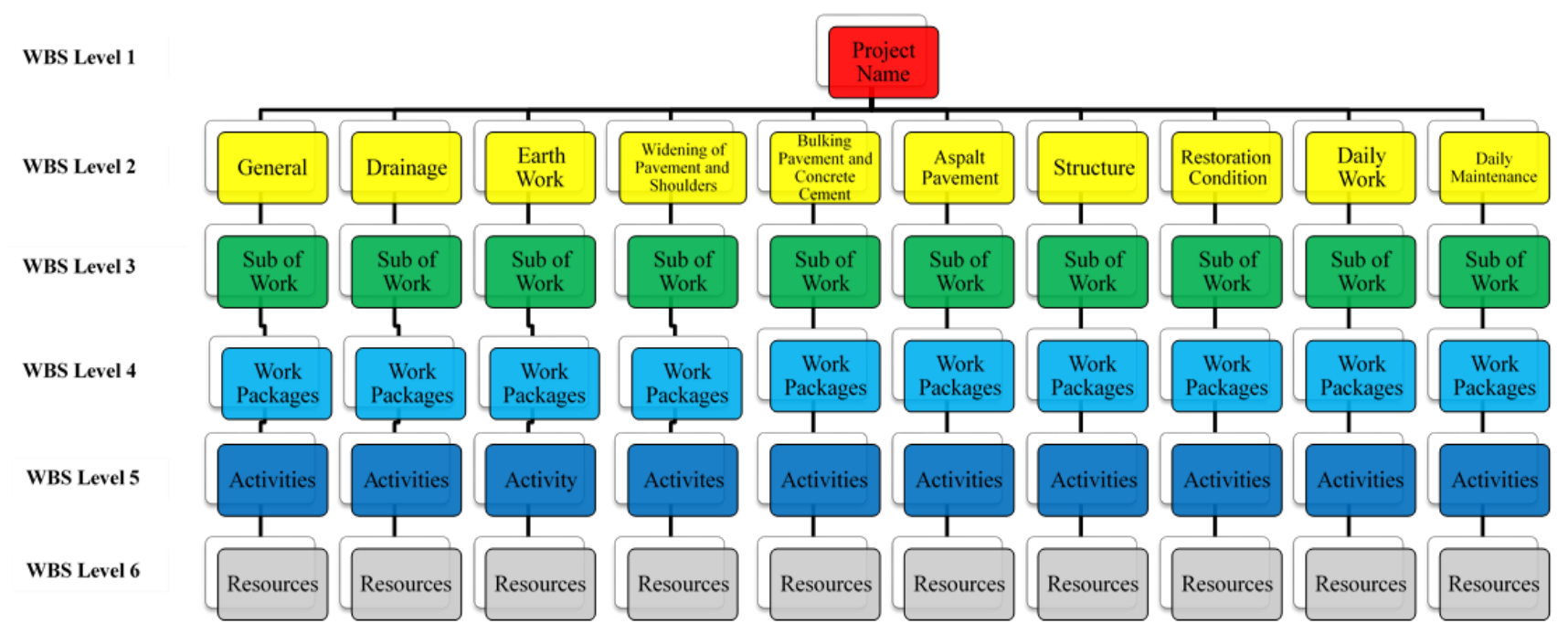

Fig. 2. WBS for Lower Structure Steel Bridge

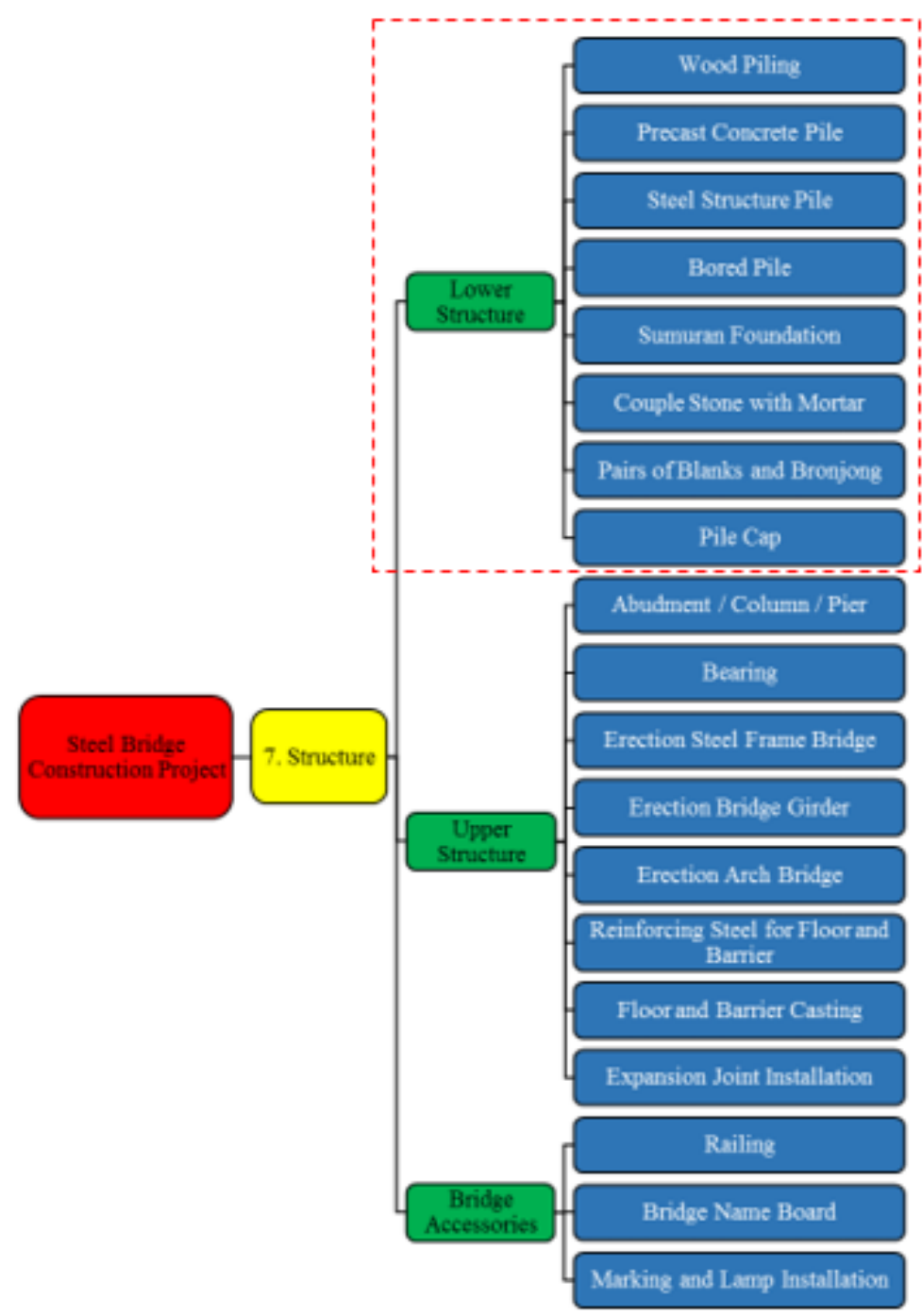

Fig. 3. The details of WBS structural division for steel bridge 
The development of the WBS dictionary on the substructure in steel bridge was carried out after WBS bridge steel construction was validated. The WBS dictionary will describe the detail of each element contained in the work packages on the substructure in steel bridge.

The WBS dictionary will contain more detailed information on each work package on the substructure in steel bridge, where the WBS dictionary contains information on:

- Code every level WBS

- WBS level color code

- Deliverable package of work

- Work package description

- Person in charge

- Job reference document

- Resources of each activity
- Detail of resources divided by material, tools and human resources.

The development phase of this WBS dictionary is validated to five experts who are experienced in the field of steel bridge construction and understand about WBS, with minimum education S2 and experience working in that field for 15 years. The end result of this WBS dictionary is the result after validation and receipt of input from the expert in which the dictionary is furnished with resources based on each activity of the structural work package of the steel bridge substructure and divided according to its tools, materials and human resources.

The following is an example of a WBS dictionary lower structure work in steel bridge for a wooden piling work package, which is as follows in Table 1.

Table 1. WBS Dictionary format - example: Wood Piling work package

\section{WBS DICTIONARY OF STEEL BRIDGE DIVISION 7/SUBSTRUCTURE Wood Piling}

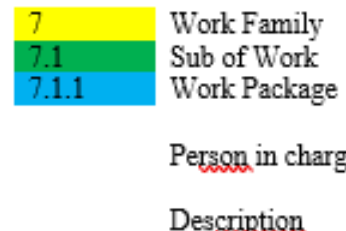

Description

Deliverable

References

\section{Structure}

Subsctructure

Wood Piling

Wooden piling should be checked first with material requirements and tolerable tolerances. All the softwood which used for piles requires preservation to be carried out as required.

Wood Piling

Contract Documents Expert Validation

\begin{tabular}{|l|l|l|l|l|}
\hline \multirow{2}{*}{ Code } & \multicolumn{2}{|c|}{ Activities } & \multicolumn{3}{|c|}{ Resources } \\
\cline { 3 - 5 } & & Human resources & \multicolumn{1}{c|}{ Material } & \multicolumn{1}{c|}{ Tools } \\
\hline 7.1 .1 .1 & \multirow{2}{*}{ Wood Pile } & 1. Workers & 1. Wood (delken) & 1. Hammer \\
\cline { 3 - 5 } & & 2. Foreman & & 2. Excavator \\
\hline
\end{tabular}

As illustrated in Table 1, the WBS dictionary for wood piling (as the work package) provides descriptions about the work package and its requirements. It includes description about its person in charge, the process / construction method of the wood piling, the product, references that can be used during the process of wood piling, its activities and required resources (consists of its labor / human resources, material and tool / equipment). Each work package for the lower structure of steel bridge was described in its WBS dictionary. This documentation is useful during the execution phase and the monitoring and controlling phase.

The final format of the WBS dictionary for the lower structure of steel bridge had also been validated in an ongoing steel bridge project constructed by Company Z. From this process, it was found that the proposed WBS dictionary for the lower structure of steel bridge could be used to guide the construction team of Company $\mathrm{Z}$ during the project execution phase. When the construction team executed one of the work packages in the field, the WBS dictionary served as the reference for confirming each of the work package's activities and respective resources. The person in charge (as written in the WBS dictionary per work package) utilized this document for monitoring and controlling the activities. Any changes or deviation from the planned activities can be assessed and adjusted using this document also. In terms of its format and contents, the respondents from Company $\mathrm{Z}$ viewed it to be easy-to-read document and informative. Thus, based on this process, the WBS dictionary for the lower structure of steel bridge is beneficial for the construction team and could be used as their guideline during project execution phase. 


\section{Conclusions}

The conclusions of this study are:

- The result of validation on WBS steel bridge project is obtained by 6 level WBS which level are, level 1 : Project name, level 2: Division / Working Group, level 3: Sub of Work, Level 4: Work Package, Level 5: Activities and Level 6: Resources.

- From WBS validation result of lower structure steel bridge construction, it can further be developed as WBS dictionary of the steel bridge lower-structure which produce validated WBS dictionary format.

- Validated WBS dictionary format contains information on: Code per WBS level, WBS level color code, Deliverable work package, Job package description, Responsible person in charge, Job reference document, Resource of each activity, Resource details divided by material, tools and human resources.

The authors would like to thank the financial support provided by Universitas Indonesia through the PITTA 2018 funding scheme managed by Directorate for Research and Public Services (DRPM) Universitas Indonesia.

\section{References}

1. Dinas Pekerjaan Umum dan Perumahan. (2015). Sejarah Perkembangan Jembatan. Retrieved from: http://dpup.slemankab.go.id/1095.slm [in Indonesian]

2. Project Management Institute. Project Management Body of Knowledge - Sixth Edition. Pennsylvania: Project Management Institute, Inc. (2013) [in Indonesian]

3. Globerson, S. Impact of various work breakdown structures on project conceptualization. International Journal of Project Management, 165-171, (1994)

4. Kerzner, H. Project Management : A Systems Approcah to Planning, Scheduling and Controlling $12^{\text {th }}$ Edition. New Jersey : John and Wiley Sons, Inc. (2017)

5. Griffin, J.A. Residential Construction Management : Managing According to the Project Lifecycle. New Jersey : J. J. Ross PublishingRoss Publishing. (2010)

6. Chen, W.-F., \& Duan, L. (2000). Bridge Engineering Handbook. New York: CRC Press.

7. Hardiyatmo, H. C. Analisis dan Perancangan Pondasi Jilid I. Yogyakarta: Gadjah Mada University Press. (2014) [in Indonesian]

8. Project Management Institute. Practice Standard for Work Breakdown StructuresSecond Edition. (2006)

9. Heldman, Kim.. PMP : Project Management Professional Exam Study Guide. New Jersey : John and Wiley Sons. Inc. (2007)
10. Stackpole C.S. A project manager's Book of Forms : A Companion to the PMBOK Guide $5^{\text {th }}$ Edition. New Jersey : John Wiley and Sons, Inc. (2013) 